\section{Procedimentos operacionais para a vigilância epidemiológica da Aids em mulheres e crianças em Pernambuco}

\section{Operational procedures for epidemiological surveillance of AIDS in women and children in Pernambuco}

Eronildo Felisberto 1

Ana Coelho de Albuquerque 2

François Figueirôa 3

Djair Sena 4

Khaled Almahnoud 5

Luciana Caroline A. Bezerra 6

Roselene Hans 7

Juliana Martins B. S. Costa 8

Silvia Cabral 9

1-9 Secretaria Executiva de Vigilância em Saúde. Secretaria Estadual de Saúde de Pernambuco. Rua Dona Maria Augusta Nogueira, 519. Bongi. Recife, PE, Brasil. CEP: 50.751-530.

E-mail: eronildo@saude.pe.gov.br

\begin{abstract}
Objectives: to divulge procedures and operational routines of epidemiological surveillance of AIDS in women and children in the state of Pernambuco in order to promote its use towards the improvement of the quality of health care.

Methods: normative and literature review, standardization and systematization of essential information on operational categories - case definition, notification, investigation, measurements of prevention, control and sampling collection.

Results: standardized operational procedures for the epidemiological surveillance of AIDS in women and children.

Conclusions: standardization and systematization associated with adequate publicizing and dissemination among health professionals and health services contributes to interventions on time and to the quality of standardized actions.

Key words Women's health, Child health, AIDS Health management
\end{abstract}

\section{Resumo}

Objetivos: divulgar os procedimentos e rotinas operacionais da vigilância epidemiológica da Aids em mulheres e crianças no Estado de Pernambuco, promovendo sua maior utilização com vistas à melhoria da qualidade da atenção à saúde.

Métodos: revisão normativa e da literatura, padronização e sistematização de informações essenciais nas categorias operacionais - definição de casos, notificação, investigação, medidas de prevenção, controle e coleta de amostras.

Resultados: procedimentos operacionais padronizados para a vigilância epidemiológica da Aids em mulheres e crianças.

Conclusões: a padronização e sistematização associada à uma adequada divulgação e disseminação entre os profissionais e serviços de saúde contribui para intervenções em tempo oportuno e com qualidade das ações normatizadas.

Palavras-chave Saúde da mulher, Saúde da criança, Aids, Gestão em saúde 


\section{Introdução}

O sistema de saúde brasileiro vem buscando aperfeiçoar seu modelo organizacional, promovendo uma maior racionalização de responsabilidades entre suas instâncias gestoras com o reconhecimento do município como o espaço privilegiado para tratar das questões setoriais. O processo de descentralização adotado, a partir da década de 1990, teve como estratégia central a transferência para os municípios da responsabilidade e dos recursos necessários para o exercício das funções de coordenação, negociação, planejamento, acompanhamento, controle, avaliação e auditoria da saúde local, controlando os recursos financeiros, as ações e os serviços de saúde prestados em seu território. Assim, os municípios foram estimulados a adquirir novas competências e capacidades político-institucionais, tendo a colaboração dos estados e da União, os quais fornecem cooperação técnica e financeira para o processo de municipalização.1,2 O papel de cada gestor é, portanto, determinante na superação dos desafios e na consolidação de um sistema de saúde comprometido com as necessidades específicas da população, presente em cada localidade brasileira.

Neste sentido cabe uma abordagem sobre procedimentos operacionais desenvolvidos na Secretaria Executiva de Vigilância em Saúde do Governo de Pernambuco, objeto do presente artigo.

A síndrome de imunodeficiência adquirida (Aids) se apresenta como doença de grande dimensão social em virtude de sua forma de transmissão e do grande número de pessoas infectadas pelo vírus da imunodeficiência humana (HIV). São cerca de 33 milhões de pessoas infectadas em todo o mundo, sendo 1,7 milhões dessas na América Latina e a prevalência no Brasil é estimada em 630.000, com aproximadamente 34.500 novos casos de Aids por ano. Em Pernambuco havia cerca de 18.000 casos notificados no período de 1983 a 2011.1,2

A epidemia no Estado tem se caracterizado por uma tendência de interiorização, pauperização, heterossexualização e feminização com o aumento de casos entre mulheres. A razão de sexo que na década de 1980 era em média de 14 homens para 1 mulher, no ano de 2011 é de 1,7 para 1. Com o aumento de casos de Aids entre mulheres, a maioria em idade fértil, verifica-se a ocorrência de casos em crianças menores de cinco anos tendo como categoria de exposição a transmissão vertical do HIV.

$\mathrm{Na}$ Secretaria Estadual de Saúde de Pernambuco (SES-PE), a vigilância epidemiológica é desenvolvida pelo Programa Estadual de Doenças Sexualmente Transmissíveis (DST/Aids) da
Diretoria Geral de Controle de Doenças e Agravos (DGCDA), vinculada a Secretaria Executiva de Vigilância em Saúde (SEVS). O trabalho, entretanto é feito em parceria com diversos setores da SES, secretarias municipais de saúde e educação e entidades da sociedade civil organizada. São realizadas ações de prevenção como elaboração, reprodução e distribuição de material informativo, folders, cartazes, cartilhas, realização de oficinas, seminários, jornadas municipais, campanhas, distribuição de preservativos, além de trabalhos de prevenção entre adolescentes nas escolas. No que diz respeito ao acesso ao diagnóstico o Programa Estadual de DST/Aids coordena uma rede de Centros Municipais de Testagem e Aconselhamento (CTA) e a prevenção da transmissão vertical do HIV, por meio do Projeto Nascer que tem como objetivo reorganizar os processos de trabalho em maternidades com vistas à melhoria da qualidade do atendimento às gestantes, puérperas e recém nascidos. Ainda, os exames de CD4 e carga viral são garantidos para todos os pacientes. A assistência tem sido fortalecida por uma rede de Serviços de Assistência Especializada (SAE), capacitação de técnicos no manejo clínico dos pacientes, promoção de grupos de adesão, distribuição de medicamentos antiretrovirais e de medicamentos de infecções oportunistas. Cerca de 14.000 pacientes são acompanhados em $22 \mathrm{SAE}$ existentes no Estado, sendo nove deles localizados na capital, dos quais quatro encontram-se situados em hospitais de referência especializada.3,4

A Vigilância Epidemiológica dos casos é implantada a partir de oficinas e treinamentos para profissionais das regionais, dos municípios e dos serviços de saúde. A análise dos dados permite a elaboração de boletins que são publicados e possibilita a disseminação das informações. Ademais, o fortalecimento da gestão municipalizada da vigilância em saúde constitui uma estratégia fundamental para assegurar o acesso integral da população à promoção, proteção e recuperação da saúde. Este fortalecimento não depende apenas do governo federal ou estadual, mas também, e principalmente, da participação decisiva dos gestores locais, em especial dos secretários municipais de saúde, para que os avanços desejados sejam obtidos.

Com vistas a contribuir com o fortalecimento da vigilância da Aids no Estado, por intermédio das ações desenvolvidas no âmbito municipal a SEVS/SES-PE elaborou em 2013, um conjunto de padronizações que oportuniza, de forma sucinta, os procedimentos e rotinas da vigilância, para que gestores e técnicos possam ter à mão informações básicas e necessárias que permitam orientar a opera- 
cionalização, em tempo oportuno e com qualidade, das ações normatizadas. 4

\section{Procedimentos Operacionais Padronizados}

\section{Definição de casos de Aids}

\section{Em crianças}

Toda pessoa com menos de 13 anos que tenha evidência laboratorial de infecção pelo vírus HIV, segundo as normas vigentes do Ministério da Saúde além de evidência de imunodeficiência. Em indivíduos menores de 18 meses de idade a evidência de infecção pelo HIV se dá através de testes de detecção de RNA viral (carga viral), em dois momentos diferentes: um primeiro exame realizado a partir do segundo mês de vida e um segundo exame com no mínimo um mês de intervalo do primeiro, necessitando ambos precisam apresentar carga viral detectável com valores acima de 1.000 cópias $/ \mathrm{mm}^{3}$.

*Critérios de definição de Aids em crianças adaptado do Centers for Disease Control and Prevention (CDC) 3 : a) doença indicativa de Aids e/ou contagem de linfócitos $\mathrm{TCD}^{+}$menor do que o esperado para a idade atual; b) óbito - menção de Aids ou termos equivalentes em algum campo da declaração de óbito e investigação epidemiológica inconclusiva (aquela que não consegue descartar o caso como Aids, porém não o encaixa em critérios existentes).

\section{Em crianças expostas ao HIV}

Todas as crianças nascidas de mães com $\mathrm{HIV}^{+}$ou com suspeita de infecção e ainda aquelas que tenham sido amamentadas por mulheres infectadas ou com suspeita de HIV (mães de leite).

\section{Em adultos}

Toda pessoa com 13 anos ou mais que tenha evidência laboratorial de infecção pelo vírus HIV, segundo as normas vigentes do Ministério da Saúde. Toda pessoa que tenha dois Testes Rápidos de HIV Reagentes. Toda pessoa que tenha um Teste ELISA HIV Reagente + Confirmatório Reagente, e preencha os critérios de definição de casos. *Critério Rio/Caracas: apresentar doenças que somem 10 pontos. ${ }^{* *}$ Critério CDC Adaptado: apresentar uma doença definidora de Aids ou contagem de células CD4 menor que 350 e Óbito - declaração de óbito com menção de Aids).

\section{Em gestantes HIV positivo}

Toda gestante que tenha evidência laboratorial de infecção pelo vírus HIV, segundo as normas vigentes do Ministério da Saúde; toda gestante que tenha dois Testes Rápidos de HIV Reagentes e toda gestante que tenha um Teste ELISA HIV Reagente + Confirmatório Reagente.

\section{Notificação dos casos}

\section{Em crianças e adultos}

Os profissionais da unidade de saúde em que o paciente for diagnosticado devem preencher a ficha do Sistema de Informação de Agravos de Notificação (Sinan - Aids criança ou Aids adulto), corretamente, de forma legível (letra de forma), sem deixar campos em branco. Não abreviar nomes. É necessária especial atenção quanto ao item "Provável Modo de Transmissão", sem omitir, supor ou inferir o dado, promovendo um diálogo aberto em que o paciente ou seu responsável possa colocar-se o mais honestamente possível sem receio de críticas. A notificação de casos de Aids é feita pelos Serviços de Assistência Especializada, para onde devem ser encaminhados todos os pacientes diagnosticados com HIV.

\section{Em crianças expostas ao HIV}

Os profissionais da unidade de saúde em que a parturiente infectada pelo $\mathrm{HIV}^{+}$for atendida devem preencher a ficha do Sinan - criança exposta ao HIV após o nascimento do concepto e preencher a ficha de gestante $\mathrm{HIV}^{+}$, se não preenchida anteriormente durante a gestação. Deve ser preenchida correta, legívelmente (letra de forma), sem campos em branco. Não abreviar nomes e ter especial atenção aos itens que informam o uso de antirretroviral, tipo de parto e aleitamento, sem omitir, supor ou inferir o dado, monitorando o seguimento correto do protocolo de prevenção da transmissão vertical do HIV e sífilis. A notificação de casos de criança exposta ao HIV é feita pelas unidades de saúde que atendem a parturiente $\mathrm{HIV}^{+}$ou ainda nos Serviços de Assistência Especializada no primeiro atendimento da criança exposta.

\section{Em gestantes HIV positivo}

Os profissionais de saúde da unidade em que a gestante for diagnosticada devem preencher a ficha do Sinan gestante $\mathrm{HIV}^{+}$, corretamente, de forma legível (letra de forma), sem deixar campos em branco. Não abreviar nomes. As fichas devem ser disponibilizadas nos serviços de pré-natal, Unidades Básica de Saúde (UBS), Unidades de Saúde da Família (USF), maternidades e ambulatórios materno-infantis públicos e privados que atendem a mulher gestante.

\section{Fluxo da Notificação}

Os profissionais da unidade de atendimento em que o paciente for diagnosticado devem preencher a ficha do 
Sinan e remetê-la para a Vigilância Epidemiológica (VE) do município. A VE do município, por sua vez, deve revisar as fichas recebidas das unidades de saúde e resgatar os dados que estiverem faltando. Posteriormente, devem digitar todas as fichas no Sinan e fazer uma transferência semanal de dados para a VE da Gerência Regional de Saúde (Geres).

\section{Investigação}

\section{Em crianças}

Verificar o que motivou a não realização ou o diagnóstico tardio da mãe e a não adoção das medidas de prevenção da transmissão vertical do HIV.

\section{Em crianças e adultos}

Nos casos de Aids por transfusão de sangue, comunicar a Geres e iniciar uma investigação in loco para rever prontuário, identificando e confirmando a transfusão anterior ao diagnóstico. Uma vez confirmado, comunicar ao Programa Estadual para continuidade da investigação junto à Agência Pernambucana de Vigilância Sanitária (APEVISA); nos casos de transmissão por usuário de drogas injetáveis (UDI), verificar se o paciente fez uso realmente de droga injetável e tem essa exposição como o provável meio de transmissão do HIV. O uso de outras drogas pode contribuir para o aumento da vulnerabilidade à infecção, mas não define a classificação do provável meio de transmissão na ficha. Nos casos que entram no banco do Sinan por óbito deve ser feita investigação para verificar o que motivou o não diagnóstico precoce e a não notificação anterior do caso. Lembrar que todos os dados são confidenciais e que as ações de investigação não podem levar a uma quebra dessa confidencialidade.

\section{Em crianças expostas ao HIV}

Monitorar o fluxo das maternidades com a notificação da criança exposta ao HIV e sucessiva referência em tempo hábil nos SAE.

\section{Em gestantes HIV positivo}

Analisar as causas da não realização ou realização tardia dos testes na gestante (que devem ser feitos nas primeiras consultas e no início do terceiro trimestre da gestação e, na maternidade na entrada para o parto); verificar no caso de gestante $\mathrm{HIV}^{+}$se o companheiro também foi testado; verificar se a gestante $\mathrm{HIV}^{+}$foi encaminhada para um Serviço de Assistência Especializada; verificar se a parturiente $\mathrm{HIV}^{+}$, assim como o recém-nascido, receberam as medidas profiláticas da transmissão vertical do HIV. ${ }^{5}$

\section{Medidas de Prevenção}

\section{Em crianças}

A transmissão vertical (mãe-filho) é o principal modo de transmissão do HIV em crianças. Assim, a medida de prevenção é diagnosticar precocemente a gestante $\mathrm{HIV}^{+}$no pré-natal e/ou parto e fazer corretamente o seguimento da mesma: antirretrovirais na gestação e parto, parto cesário eletivo (dependendo da carga viral da mãe), inibição da lactação com o fornecimento de fórmula infantil, xarope de AZT para criança desde o nascimento até 42 dias de vida (Protocolo PACTG 076 - disponível em www.aids.gov.br).

\section{Em crianças expostas ao HIV}

Ações de educação em saúde com o estímulo ao uso sistemático do preservativo como forma de evitar as doenças sexualmente transmissíveis e em especial o HIV; estímulo a testagem anti-HIV nas mulheres juntamente com os seus parceiros sexuais antes de iniciarem as relações desprotegidas com o objetivo de engravidar, bem como na atenção ao prénatal, testando a gestante, esclarecendo sobre os benefícios do diagnóstico precoce para a utilização do protocolo da prevenção da transmissão vertical do HIV e sífilis.

\section{Em adultos}

Estimular as medidas de prevenção entre a população geral e grupos de maior vulnerabilidade: uso correto e sistemático do preservativo em todas as relações sexuais, não compartilhamento de instrumentos perfuro cortantes, realização de testagem para infecção pelo HIV.

\section{Em gestantes HIV positivo}

Estimular as mulheres a se testarem juntamente com o companheiro, antes de iniciarem as relações desprotegidas (sem preservativo) com o objetivo de engravidar; orientar as gestantes que permanecem em vulnerabilidade para a infecção pelo HIV a continuarem usando preservativo durante a gravidez. Os casais soro-discordantes devem ser acompanhados nos SAE para planejamento da gravidez. ${ }^{6}$

\section{Controle}

\section{Em crianças}

Captação precoce da gestante para o inicio do pré-natal (importância de realizar o teste anti-HIV no $1^{\circ}$ e $3^{\circ}$ trimestres gestacionais, bem como no parto); documentar a sorologia da gestante na carteira de gestante; notificar o caso de gestante (a 
fim de fazer o seguimento gestacional com o PACTG 076); prevenção da transmissão sexual (informação e educação visando a prática do sexo seguro); prevenção da transmissão sanguínea (triagem dos hemoderivados com testes de detecção para o HIV inclui-se a triagem da gestante a fim de evitar a transmissão para o filho).

\section{Em crianças expostas ao HIV}

Promover ações de aconselhamento à prevenção de doenças sexualmente transmissíveis e Aids nos serviços de saúde, especialmente na atenção prénatal; captar precocemente as gestantes para o início do pré-natal (importância de realizar o teste antiHIV nas primeiras consultas no início do $3^{\circ}$ trimestre e na entrada da maternidade no início do trabalho de parto); documentar a sorologia da gestante na carteira de gestante; notificar o caso de gestante $\mathrm{HIV}^{+}$; notificar a criança exposta ao HIV; disponibilizar os antirretrovirais para as gestantes e parturientes $\mathrm{HIV}^{+}$e crianças expostas; disponibilizar a fórmula láctea infantil para a criança exposta ao HIV como forma de garantir a substituição do leite materno; disponibilizar os inibidores de lactação para as parturientes $\mathrm{HIV}^{+}$evitando assim a amamentação e possível transmissão do vírus para o recém nascido. 6,7

\section{Em adultos}

Todas as Unidades Básicas de Saúde devem realizar ações contínuas de prevenção as DST/Aids no seu território. Realizar ações extramuros incluindo saúde e prevenção nas escolas. Priorizar grupos mais vulneráveis. Promover e facilitar a distribuição de preservativos.

\section{Em gestantes HIV positivo}

Deve ter início nas ações de atenção ao pré-natal, quando se esclarece à gestante sobre os benefícios do diagnóstico precoce do HIV. Neste sentido, as UBS, os serviços de pré-natal e de saúde da mulher devem garantir o acesso ao teste anti-HIV e promover ações de aconselhamento pré e pós-teste. Além disso, a disponibilização de preservativos masculinos e femininos faz parte de todo o processo educativo, inclusive, das ações dirigidas aos casais soro-discordantes.

\section{Referências}

1. Brasil. Ministério da Saúde. Departamento de DST, Aids e Hepatites Virais. Aids/DST 2010. Bol Epidemiol. 2010; 8: 3-24.

\section{Coleta de amostras}

\section{Em crianças e adultos}

Todas as UBS devem realizar o aconselhamento pré-teste; realizar o Teste Rápido (TR) anti-HIV, se possível. Realizar coleta de sangue para o Teste ELISA HIV ou encaminhar para uma unidade de maior complexidade ou Centro de Testagem e Aconselhamento (CTA).

\section{Em crianças expostas ao HIV}

Em todas as unidades de saúde deve ser realizado o aconselhamento pré-teste e, se disponível, deve ser realizado o teste rápido anti-HIV para todas as gestantes. Caso não esteja disponível o TR, realizar o aconselhamento pré-teste e coletar amostra de sangue para o Teste ELISA HIV.7 Caso não seja possível realizar a coleta, encaminhar a gestante para uma unidade de saúde de maior complexidade ou para o CTA.

\section{Em gestantes HIV positivo}

Os testes devem ser realizados nas primeiras consultas de pré-natal, no início do terceiro trimestre e na maternidade quando do início do trabalho de parto.

\section{Considerações finais}

A Vigilância em Saúde guarda peculiaridades e especificidades ao integrar o sistema nacional de saúde e é notória a variação na implantação e descentralização das ações, o que gera preocupações em torno da qualificação dos processos de gestão. Cumprindo, assim, com seu papel de planejamento, de qualificação dos trabalhadores da área, e de cooperação técnica, além da execução suplementar de ações - quando constatada insuficiência por parte dos municípios - a Secretaria Executiva de Vigilância em Saúde da Secretaria Estadual de Saúde do Governo de Pernambuco traz, neste informe, a sua contribuição com o objetivo de apoiar o desenvolvimento das ações de controle da Aids.4,6
2. Santos EM, Reis AC, Westman S, Alves RG. Avaliação do grau de implantação do programa de controle da transmissão vertical do HIV em maternidades do "Projeto Nascer”. Epid Serv Saúde. 2010; 19: 257-69. 
3. CDC (Centers for Disease Control and Prevention). Revised recommendations for HIV screening of pregnant women. MMWR Morb Mortal Wkly Rep. 2001; 50(RR19): 63-86.

4. Governo de Pernambuco. Secretaria Estadual de Saúde. Secretaria Executiva de Vigilância em Saúde. Guia para Gestão da Vigilância em Saúde: procedimentos operacionais padronizados. 1 ed. Recife; 2013.

5. Brasil. Ministério da Saúde. Pré-natal e puerpério: atenção qualificada e humanizada. Manual Técnico. Brasília; 2005.
6. Brasil. Ministério da Saúde. Secretaria de Vigilância em Saúde. Programa Nacional de DST e Aids. Protocolo para a prevenção de transmissão vertical de HIV e sífilis. Manual de Bolso; 2007.

7. Szwarcwald CL, Barbosa Júnior A, Souza Júnior PRB, Lemos KRV, Frias PG, Luhm KR, Holcman MM, Esteves MAP. HIV testing during pregnancy: use of secondary data to estimate 2006 test coverage and prevalence in Brazil. Braz J Infect Dis. 2008; 12: 167-72.

Recebido em 15 de dezembro de 2012

Versão final apresentada em 15 de janeiro de 2013

Aprovado em 30 de janeiro de 2013 